\title{
Experiences of perceived vs actual time required for data management on electronic data capture clinical trials in a non commercial setting
}

Nancy Tappenden*, Lindsey Masters

From 2nd Clinical Trials Methodology Conference: Methodology Matters

Edinburgh, UK. 18-19 November 2013

The traditional method of data management at the MRC Clinical Trials Unit has been for paper CRFs to be completed by accredited sites and sent in to a coordinating data centre. There the data is entered on to a trial database and cleaned. However there has been a shift recently within our unit towards electronic data capture, whereby sites enter data directly into the trial database. Data monitoring is done at the coordinating centre and cleaning occurs at both the coordinating centre and site.

The perception is that this method provides better data quality and essentially reduces the amount of time needed for data management at the co-ordinating data centre. Experience so far has shown that this may not be the case. The time required for data management is in fact directed toward less common tasks such as training and ongoing assistance to site staff in using the trial database. It appears that there is increased resource required for the database programmers due to novel data capture methodologies. There also seems to be an increase in the time spent at sites on collecting and entering the data, especially if, due to clinic conditions, they are completing paper CRFs first before data entry.

In this presentation, we shall explore the data management activities being undertaken in these trials and compare them to a similar trial employing the more traditional model described above.

Published: 29 November 2013

MRC Clinical Trials Unit Hub for Trials Methodology Research, London, UK
doi:10.1186/1745-6215-14-S1-013

Cite this article as: Tappenden and Masters: Experiences of perceived vs actual time required for data management on electronic data capture clinical trials in a non commercial setting. Trials 2013 14(Suppl 1):013.
Submit your next manuscript to BioMed Central and take full advantage of:

- Convenient online submission

- Thorough peer review

- No space constraints or color figure charges

- Immediate publication on acceptance

- Inclusion in PubMed, CAS, Scopus and Google Scholar

- Research which is freely available for redistribution
() Biomed Central 